\title{
THE VALUES AND (INTER) CULTURAL PRACTICES OF STUDENTS IN FRANCE AND ARMENIA
}

Derhy Kurtz B. W. L. (Enseignant Chercheur Université Catholique de Lyon, Lyon, France)

benjamin.derhy-kurtz@univ-avignon.fr

Basco L. (Enseignant Chercheur Laboratoire Culture \& Communication Avignon Université, Avignon, France) louis.basco@univ-avignon.fr

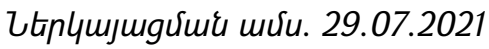

9püunuर्uाi mर्रu. 09.08.2021

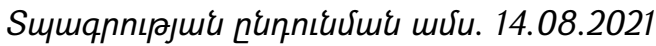

The article presents the continuation of joint research projects initiated, as a result of which it be-came possible to study the differences in the perception of the student audience, which are located, on the one hand, in France, and on the other hand, in Armenia. This made it possible to identify connections and interactions between the personal values of students and their practice. Spiritual or religious values, family values, artistic values, values associated with pleasure and / or self-realization, values associated with freedom and values associated with new technologies were especially studied. This stage of the study made it possible to establish in what forms and under what conditions the connections of values and (inter) cultural practices are manifested. With regard to intercultural interaction and exchange between the two countries, it was possible to describe, explain and measure how the gaps in the perception of the student image representations as a person in France and in Armenia could be noted.

Keywords: student, values, (inter) cultural practices, interaction, personality, selfrealization.

DOI: https://doi.org/10.46991/SBMP/2021.4.2.128

Introduction ${ }^{1}$. Following the research projects initiated, it was possible to study the differences in reception from an audience (in particular from a student audience) to another, which are located on the one hand in France and on the other hand in Armenia, and to look at the links and interactions between their personal values and their student practices. Spiritual and / or religious values, family values, artistic values, values linked to pleasure and / or self-realization, values linked to freedom and values linked to new technologies have been specifically studied.

Symposium by Benjamin W. L. DERHY KURTZ 


\section{French students}

Family values. For French students, family values revolve around the issues of heritage, identity and memory. They see life as taking root within the family, which is considered to be the starting point in the construction of their identity. Students affirm attachment to their family. Family values are based on traditions (roots), transmission and education. The students recognize the importance of respecting certain rituals of family life, especially the typical, recurring, events, such as family reunions around a meal.

Students' mottos make reference to family as the heart of all events. Family is seen by the participants as a space within which everything takes pace, which will always be there, no matter what. Furthermore, they express the idea that family is vital: that when it is not there, one does not feel well. The emblems are a tree or hands extended towards the same thing. The tree can be understood as a symbol of rootedness, growth and life; a symbol that one finds in a genealogical tree, for instance, which in itself represents an entire family.

"Positive" values evoked by the participating students have to do with love, sharing, transmission and support. Positive practices linked to the coat of arms are sharing moments or listening moments.

"Negative" values addressed by students rather allude to a form of abandonment, resulting from indifference, intolerance, selfishness, betrayal or cowardice. With regards to negative practices, the notion of mistreatment, towards either children or adults, is underlined; amoral values such as incest are also evoked.

Artistic values. Mottos and emblems refer to sharing and exchanging, here.

Either this is directly translated into words, or can be represented through an image, such as a cake divided into parts. The French public educational system brings to French children, through its open policy, pluridisciplinarity. French students do not only mention classic arts such as music or painting, but go further by mentioning other art forms as well. Positive practices are cultural practices, such as attending or participating to arts activities, representations or exhibits, as well as other forms, such as French gastronomy. Social stigma can be perceived as being linked to values which a number of French students do no adhere to, as well as to a negative representation of notions such as elitism and savant knowledge (as opposed to, for instance, popular culture). Artistic practices are recognized as important elements which have been facilitated in recent years thanks to initiatives and events undertaken by the students themselves within associations (such as concerts within the university).

Religious or spiritual values. Students feel that they are more in a spiritual than a religious commitment. Indeed, few of them testify to a religious practice. Many of them, nevertheless, are looking for ways that would allow them more serenity, or 
inner peace, in their student life. Artistic practices are recognized as important elements which have been facilitated in recent years thanks to initiatives and events undertaken by the students themselves within associations (such as concerts within the university).

\section{Armenian students}

Freedom values. According to the mottos, freedom is linked to the notion of choice and, therefore, decision. The resulting emblems are very often the representation of a bird and more particularly of a dove to evoke freedom and escapism.

Regarding the "positive" values mentioned by the students interviewed, they revolve around creativity and life. When it comes to positive values and practices, freedom opens up possibilities and allows individuals to be creative. It is accompanied by the notion of responsibility: free individuals must take responsibility for their actions, but this balance of freedom / responsibility could also be seen as a vector of inner peace. Regarding the "negative" values mentioned, we can find inner conflict, self-forgetfulness or even a lack of order. Under that perspective, freedom would induce disorder, neglect and even internal conflict, and could be seen as giving individuals the opportunity to take negative actions.

Self-actualization values. All of the mottos found in these coats of arms revolve around the notions of achievement, trust or continuity. Self-realization can be seen as being linked to freedom in two possible manners: either as self-realization being possible when individuals evolve in an environment which leaves them free or as self-realization contributing to the freedom of individuals. Self-realization also seems to be linked to the idea of transmission / "continuity".

The resulting emblems are very often representations of the individual. As for the so-called positive values, they revolve around the self-satisfaction, through the self-confidence. Self-realization would here allow one to develop self-confidence, to be aware and to open up to possibilities.

Self-realization can be seen as being part of a dynamic process as pupils / students speak of a "constant effort towards a goal", of a "drive towards activity" and of "personal development". Regarding the so-called negative values mentioned by the students, one can find interior inaccessibility, interior conflict or even "infinity". Indeed, the notion self-realization can induce a feeling of perdition in individuals while facing infinite possibilities. In addition, the pursuit of self-actualization can come up against limits or a feeling of limit which ultimately causes a feeling of dissatisfaction in the individual.

New technologies values. The responses to the different elements of the coat of arms were more varied for these values than for others: could this be because digital culture is more recent, or "moving" as being in constant evolution? For mottos, digital technology appears to allow you to choose from a wide range of 
information. The effectiveness of "digital" is underlined, but its usefulness is sometimes questioned. All of the mottos noted in these coats of arms revolve around the concepts of using digital technology wisely. The resulting emblems are very often the representation of microelectrical diagrams in order to show the "man-machine". As for the positive values mentioned by those interviewed, they revolve around time management, flexibility, efficiency or the network. Values that can be found in the practices put forward include transmission, efficiency and sharing. With regard to positive values and practices, digital technology is thus linked to saving time ("speed", "ease"), and considered to allow communication, openness and that is ultimately has a role to play in our social environment.

Regarding the negative values mentioned, time, manipulation, loss of freedom or conflict were recuring occurrences. Values that can be found in everyday situations as shown by the examples mentioned include loss of self-esteem or excess. According to interviewees, digital culture would, generate stress, over-information would facilitate manipulation and individuals would "forget a part of themselves" by the prevalence of virtual reality on the physical world.

Religious or spiritual values. The mottos center around the notion of faith, associated either with love or strength, and sometimes with something described as an inexplicable "unity". The tree, a symbol of strength and ascension, is here seen as representing spiritual or religious values. Regarding positive values and practices, respondents state that religion or a type spirituality brings a form of confidence, nourishes the spirit and would prevent loneliness. Negative values and practices, on the other hand, point to the dogmatism present in religion as well as to possible deviations (in particular fanaticism). Students seem to disapprove of the limits to conduct brought about by religion or spirituality.

Artistic values. The mottos discussed by interviewed students are doublefaceted, here: at the same time, they allow to know oneself ("interior") and they are the symbol of beauty and even of a certain national grandeur (exterior).

Positive values and practices concern all that is self-expression and openness to others. Art and what surrounds it would make it possible to go beyond rules and limits, but also to accept others and other ideas.

Family values. The mottos discussed here have to do with trust, love and warmth, described as being present in the family institution. Regarding "positive" values and practices, we find the notion of disinterested love: the family unit appears as a place of listening, support and tolerance; sometimes even a place of unfailing "dedication".

Negative values and practices, on the contrary, the family is also the place where pupils / students feel deprived of their privacy. Children would be the instruments of their parents and subject to family dogma. Some interviewees also speak of problems of "betrayal" and "dishonor" within families. The negative values 
and practices can be seen through the perceived limits within art, for instance through the conformism which can exist in the art sector. The students also associate the art world with a certain rivalry between "actors" of this sector and "belated recognition".

In conclusion. The students testify in particular in what ways they can highlight the link between their values and (inter)cultural practices. This study has allowed to establish in what forms they manifest themselves, and under what conditions. In terms of interculturality and exchange between the two countries, it was possible to describe, explain and measure how gaps can be noted in the reception of representations of the image of the student as a person in France and in Armenia.

\section{Reference}

1. Basco L. (2010), Le lien étudiant, Revue Chemins de formation au fil du temps n¹5, Téraède, Université de Nantes, pp. 168-178.

2. https://www.agenda-2030.fr/odd/odd4-veiller-ce-que-tous-puissent-suivreune-education-de-qualite-dans-des-conditions-dequite

3. https://www.chroniquesociale.com/index.php?ID=1011991\&dataType=cata \&keyWords=louis+basco+accompagner+l+\%C3\%A9tudiant+louis+basco\&x $=0 \& \mathrm{y}=0 \mathrm{La}$ personne étudiante 